\title{
Comparison of the acute effects of salbutamol and terbutaline on heart rate variability in adult asthmatic patients
}

\author{
B. Eryonucu*, K. Uzun", N. Güler*, M. Bilge*
}

Comparison of the acute effects of salbutamol and terbutaline on heart rate variability in adult asthmatic patients. B. Eryonucu, K. Uzun, N. Güler, M. Bilge. (C)ERS Journals Ltd 2001

ABSTRACT: This study investigated the effects of $\boldsymbol{\beta}_{2}$-adrenergic agonist therapy on heart rate variability (HRV) in adult asthmatic patients by using frequency domain measures of HRV.

A randomized crossover design was used. Twenty adult patients with asthma were studied. All patients showed a mild-to-moderate decrease in baseline forced expiratory volume in one second. Any diseases that might have influenced the autonomic function were excluded. All patients had a complete physical examination and medical history that revealed no cardiovascular disease or medication. The study used $200 \mu \mathrm{g}$ inhaled salbutamol and $500 \mu \mathrm{g}$ inhaled terbutaline. HRV analysis was performed for each 5-min segment, 5 min before inhalation of the study drug and 5, 10, 15, 20, 25 and $30 \mathrm{~min}$ after inhalation. Total power (TP: $<0.40 \mathrm{~Hz}$ ), high-frequency power (HF: $0.15-0.40 \mathrm{~Hz}$ ), low-frequency power (LF: $0.04-0.15 \mathrm{~Hz}$ ) and $\mathrm{LF} / \mathrm{HF}$ ratio were calculated.

The $\mathrm{LF}$ and $\mathrm{LF} / \mathrm{HF}$ ratio increased and TP decreased at 5, 10, 15 and $20 \mathrm{~min}$ after the salbutamol and the terbutaline inhalation, HF did not change significantly after the salbutamol and terbutaline inhalation.

Acute salbutamol and terbutaline inhalation produce similar effects on heart rate variability and increase sympathetic modulation in the cardiac autonomic activity.

Eur Respir J 2001; 17: 863-867.
Depts of, *Cardiology and ${ }^{*}$ Chest Diseases, Medical Faculty, Yüzüncü Yil University, Van, Turkey

Correspondence: B. Eryonucu

Yüzüncü Yıl Üniversitesi

Tıp Fakültesi Kardiyoloji AD

65200

Turkey

Fax: 904322168352

Keywords: Asthma

heart rate

inhalation

therapeutics

Received: August 282000

Accepted after revision January 17 2001
In clinical cardiology, heart rate variability (HRV) is a valuable noninvasive tool for assessment of autonomic cardiovascular function. Indexes of the HRV reflect cardiac autonomic tone $[1,2]$. Decreased HRV is associated with increased mortality and morbidity with various forms of heart disease including myocardial infarction, congestive heart failure and chronic mitral regurgitation [3-10].

The autonomic nervous function of asthmatic children was decreased in comparison to the normal subjects. Further, the autonomic nervous function of asthmatic patients, even in the normal condition in which the patient is free of an asthma attack, differs from that of normal children [11]. In addition, sympathetically mediated HRV (normalized low frequency power) was significantly lower in both asymptomatic and acute asthmatic patients compared to healthy controls. All these findings are consistent with altered sympathetic/parasympathetic regulation of heart rate in subjects with bronchial asthma [12].

Inhaled short acting $\beta_{2}$-adrenergic agonists are the most effective bronchodilator agents available for the treatment of asthma. Side-effects of $\beta$-agonists generally stem from activation of $\beta_{1}$-receptors. Cardiovascular effects include tachycardia, palpitation, dysrhythmias, exacerbation of myocardial ischemia, and hypo- or hypertension. These findings suggest that $\beta_{2}$-adrenergic agonists may interfere with autonomic cardiovascular function $[13,14]$.

Although the effects of salbutamol on HRV in asthmatic children have been established, the effects of $\beta_{2}$-adrenergic agonist therapy, such as salbutamol and terbutaline, on HRV in asthmatic adult patients have not been established [15]. The primary aim of this study was to assess the effect of $\beta_{2}$-adrenergic agonist therapy on HRV in patients with asthma by using frequency domain measures of HRV. In addition, evaluation of whether the effects of a salbutamol differed from those of terbutaline was undertaken.

\section{Material and methods}

\section{Study subjects}

Twenty patients (mean age $37 \pm 6$ (range 28-47)) with newly diagnosed or known cases of bronchial asthma were studied. Asthmatic patients were selected consecutively according to the American Thoracic Society guidelines [16]. None of the patients had been receiving oral or inhaled asthma medication $\left(\beta_{2-}\right.$ agonists and corticosteroids) for the previous 2 months. All patients subjects showed mild-to-moderate decrease in baseline forced expiratory volume in one 
second. Patients with diabetes mellitus, renal disorders or any diseases that might have influenced the autonomic function were excluded. All patients had a complete physical examination and medical history that revealed no cardiovascular disease or medication. Blood chemistry and urine tests were within normal ranges. Patients also had normal blood pressure, electrocardiography (ECG) and transthoracic echocardiography. The clinical characteristics of patients are shown in table 1. All patients gave informed consent to the study, which had been approved by the hospital ethical committee.

\section{Study design}

The study followed a randomized and crossover design. The patients were studied twice, 3 days apart. The studies were performed between $09.00 \mathrm{~h}$ and $12.00 \mathrm{~h}$ to avoid circadian variation of HRV parameters.

\section{Study drug}

The study used $200 \mu \mathrm{g}$ inhaled salbutamol via pMDI (salbutamol aerosol, Ventolin, GlaxoWellcome, UK) and $500 \mu \mathrm{g}$ inhaled terbutaline also via pMDI (terbutaline aerosol, Bricanyl, Astra, Sweden). The salbutamol dose was given by administering two $100 \mu \mathrm{g}$ doses, while the terbutaline dose was given by administering two $250 \mu \mathrm{g}$ doses. The subjects directly inhaled the drug without a spacer device after full expiration and then hold their breath for $10 \mathrm{~s}$.

\section{Holter monitoring and heart rate variability analysis}

The ambulatory ECGs were recorded by a Del Mar Avionics 483 digicorder recorder (Irvine, CA, USA) $30 \mathrm{~min}$ before and $1 \mathrm{~h}$ after drug inhalation. All Holter recordings were obtained at supine rest. The subjects quietly breathed during the holter recordings. These recordings were analysed using computer software (Holter analysis system, Del Mar). All recordings were visually examined and manually over-read to verify beat classification. Abnormal beats and areas of artefact were automatically and manually identified

Table 1. - Patients characteristics

\begin{tabular}{lc}
\hline Characteristics & Value \\
\hline Sex female/male & $11 / 9$ \\
Age yr & $37 \pm 6$ \\
smoking history n & 3 \\
$\mathrm{pH}$ & $7.38 \pm 0.02$ \\
$\mathrm{PCO}_{2} \mathrm{mmHg}$ & $41.5 \pm 2.1$ \\
$\mathrm{PO}_{2} \mathrm{mmHg}$ & $98 \pm 2$ \\
$\mathrm{FEV} 1 \%$ pred & $67 \pm 10$ \\
FEV1/FVC & $75 \pm 9$ \\
\hline
\end{tabular}

Data are presented as absolute numbers or as mean \pm SD. FEV1: forced expiratory volume in one second; FVC: forced vital capacity. and excluded from the analysis. All patients were in sinus rhythm throughout the recordings. The frequency domain analysis of HRV was performed by a fast Fourier transformation. HRV analysis was performed and mean heart rate (HR) calculated for 5 min before inhalation of the study drug and during 6 sequential, 5-min intervals starting after the inhalation of study drugs. The frequency domain variables $\left(\mathrm{ms}^{2}\right)$ considered in this analysis were: total power (TP: $<0.4 \mathrm{~Hz}$ ); high-frequency power (HF: $0.15-40 \mathrm{~Hz}$ ); lowfrequency power (LF: $0.04-0.15 \mathrm{~Hz}$ ); and $\mathrm{LF} / \mathrm{HF}$ ratio.

\section{Statistical analysis}

Data are presented as mean $\pm \mathrm{SD}$. The normal distribution of the variables was evaluated using Kolmogorov-Smirnov tests. Measures of frequency domain indices of HRV were log transformed because they were not normally distributed. Data between the groups were compared with Chi-squared test or Fisher's exact test and unpaired two-tailed t-test. The changes of HRV parameters after inhalation of the study drugs were compared with repeated measures of the variance analysis. A two-tailed p-value $<0.05$ was considered significant.

\section{Results}

The changes of HRV parameters after inhalation of the study drugs are shown in table 2 and figures $1-3$. The changes of HRV parameters after the salbutamol and terbutaline inhalation were similar in the two groups. The changes of HRV parameters in each 5 min segment in the salbutamol group were not statistically significantly different when compared to the same segment in the terbutaline group. HR, LF and LF/HF ratio increased and TP decreased at 5, 10, 15 and $20 \mathrm{~min}$ after both the salbutamol and terbutaline inhalation. The highest $\mathrm{LF}$ and $\mathrm{LF} / \mathrm{HF}$ ratio values were observed $5 \mathrm{~min}$ after the salbutamol and terbutaline inhalation and the HF did not change significantly after the salbutamol and terbutaline inhalation.

\section{Discussion}

The presented findings show that both salbutamol and terbutaline have acute effects on autonomic cardiovascular function in asthmatic adult patients. The analysis of HRV showed that inhalation of salbutamol and terbutaline decreased TP and increased LF/HF and LF. The effects of salbutamol on HRV did not differ from those of terbutaline.

In previous studies, the asthmatic children had an increased parasympathetic drive and decreased sympathetic drive as compared to healthy children. The different autonomic nervous function of asthmatic children is related to the severity of the asthma [11, 17]. In addition, $\beta_{2}$-agonist medication increases sympathetic cardiovascular activity in asthmatic children [18]. Asthmatic children receiving fenoterol showed an 
Table 2. - The changes of heart rate variability parameters after salbutamol and terbutaline inhalation

\begin{tabular}{|c|c|c|c|c|c|c|c|c|c|c|}
\hline \multirow{2}{*}{$\begin{array}{l}\text { Time } \\
\text { period } \\
\text { min }\end{array}$} & $\begin{array}{c}\text { Heart } \\
\text { rate }\end{array}$ & $\mathrm{TP}$ & LF & $\mathrm{HF}$ & LF/HF & $\begin{array}{l}\text { Heart } \\
\text { rate }\end{array}$ & TP & LF & HF & $\mathrm{LF} / \mathrm{HF}$ \\
\hline & \multicolumn{5}{|c|}{ Terbutaline } & \multicolumn{5}{|c|}{ Salbutamol } \\
\hline Baseline & $74 \pm 3$ & $3.78 \pm 0.11$ & $2.32 \pm 0.11$ & $2.90 \pm 0.14$ & $0.80 \pm 0.04$ & $74 \pm 4$ & $3.74 \pm 0.12$ & $2.29 \pm 0.14$ & $2.94 \pm 0.13$ & $0.77 \pm 0.04$ \\
\hline $0-5$ & $79 \pm 3$ & $41 \pm 0.10^{\bullet}$ & $2.65 \pm 0.08$ & $2.87 \pm 0.12$ & $0.92 \pm 0.04$ & $81 \pm 3^{\pi}$ & $3.51 \pm 0.11^{\Phi}$ & $2.63 \pm 0.11^{\bullet}$ & $2.87 \pm 0.13$ & $0.91 \pm 0.03^{\bullet}$ \\
\hline $6-1$ & $82 \pm$ & $09^{+}$ & \pm 0.08 & $2.91 \pm 0.13$ & $0.95 \pm 0.06$ & $84 \pm 4^{+}$ & $3.49 \pm 0.10$ & $2.77 \pm 0.13^{\bullet}$ & $2.89 \pm 0.14$ & $0.96 \pm 0.05^{+}$ \\
\hline & $85 \pm 4^{+}$ & 8 & $2.73 \pm 0.10$ & .09 & $0.94 \pm$ & $85 \pm 4^{+}$ & $3.42 \pm 0.14^{\circ}$ & $2.74 \pm 0.12$ & $2.86 \pm 0.15$ & $0.95 \pm 0.03^{\circ}$ \\
\hline & $82 \pm 2^{\circ}$ & & $2.68 \pm 0.09^{\bullet}$ & 0.10 & $0.93=$ & $84 \pm 3$ & $3.58 \pm 0.12^{\bullet}$ & $2.65 \pm 0.12^{\bullet}$ & $2.86 \pm 0.14$ & $0.93 \pm 0.03^{\oplus}$ \\
\hline & $79 \pm$ & 3.5 & $2.57 \pm 0.08$ & $2.85 \pm 0.09$ & $0.89 \pm 0.09$ & $81 \pm 5^{n}$ & $3.71 \pm 0.13$ & $2.59 \pm 0.09$ & $2.90 \pm 0.09$ & $0.89 \pm 0.04$ \\
\hline $26-30$ & & \pm 0.07 & $2.50 \pm 0.07$ & $2.84 \pm 0.08$ & $0.88 \pm 0.03$ & $78 \pm 5$ & $3.75 \pm 0.13$ & $2.47 \pm 0.07$ & $2.87 \pm 0.11$ & $0.86 \pm 0.04$ \\
\hline
\end{tabular}

Heart rate variability parameters values are expressed as 10 -base logarithmic values and given as mean \pm SD. TP: total power, HF: high-frequency power, LF: low-frequency power. ${ }^{\uparrow}: \mathrm{p}<0.05$ versus baseline; ${ }^{+}: \mathrm{p}<0.01$ versus baseline.

increased adrenergic drive [17]. In concurrence with the present findings, JARTTI et al. [19] found that the acute salbutamol inhalation decreased parasympathetic drive and increased sympathetic modulation in the cardiovascular autonomic balance. Two-week salbutamol

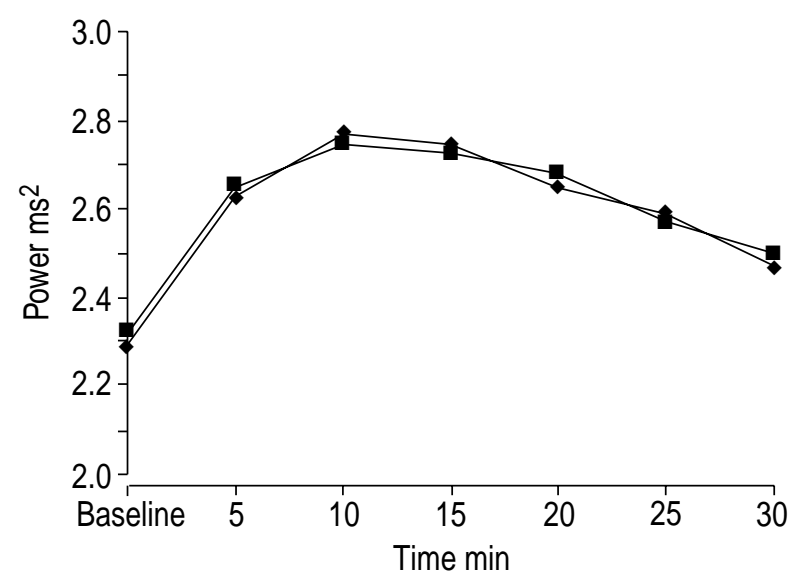

Fig. 1. - The changes of low frequency power components of heart rate variability after the salbutamol $(\bullet)$ and terbutaline (ם) inhalation. Values are expressed as 10-base logarithmic values and given as mean.

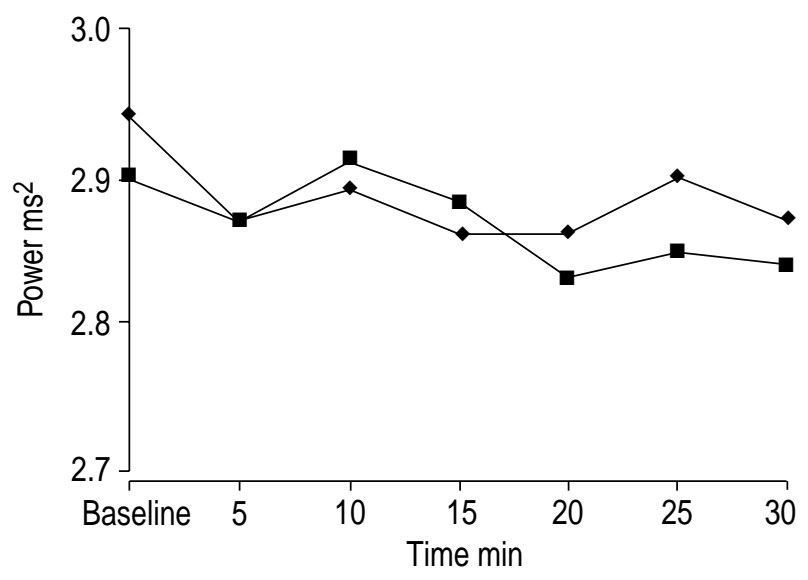

Fig. 2. - The changes of high frequency power components of heart rate variability after the salbutamol $(\bullet)$ and terbutaline (ם) inhalation. Values are expressed as 10-base logarithmic values and given as mean. treatment increased baseline LF variability and LF/ HF variability ratio of ECG R-R intervals when compared to the placebo treatment. However, different results were obtained by ROSSINEN et al. [20] who reported the commonly used doses of inhaled or nebulized salbutamol induced no acute myocardial ischaemia, arrhythmias or changes in HRV as assessed by Holter monitoring of 24 patients with coronary artery disease and clinically stable asthma or chronic obstructive pulmonary disease. A 4-week salmeterol treatment increased baseline $\mathrm{HR}, \mathrm{LF} / \mathrm{HF}$ variability ratio of $\mathrm{R}-\mathrm{R}$ intervals. This 4 -week salmeterol treatment also decreased baseline $\mathrm{HF}$ variability of R-R intervals. As a response to the acute $600 \mu \mathrm{g}$ of salbutamol, changes in $\mathrm{HR}$ and $\mathrm{HF}$ variability of $\mathrm{R}-\mathrm{R}$ intervals were significantly smaller after 4 weeks salmeterol treatment [21].

The cardiovascular actions of $\beta$-adrenergic agonists result from direct myocardial effects that increase the rate and force of contraction and from indirect rate effects that result from baroreceptor reflexes to peripheral dilation $[13,22-24]$. In the present study, inhalation of $\beta_{2}$-adrenergic agonists caused an acute and statistically significant augmentation of LF and HR and decrease of TP, which is considered to reflect sympathetic activity. Thus, the observed $\beta_{2}$-adrenergic

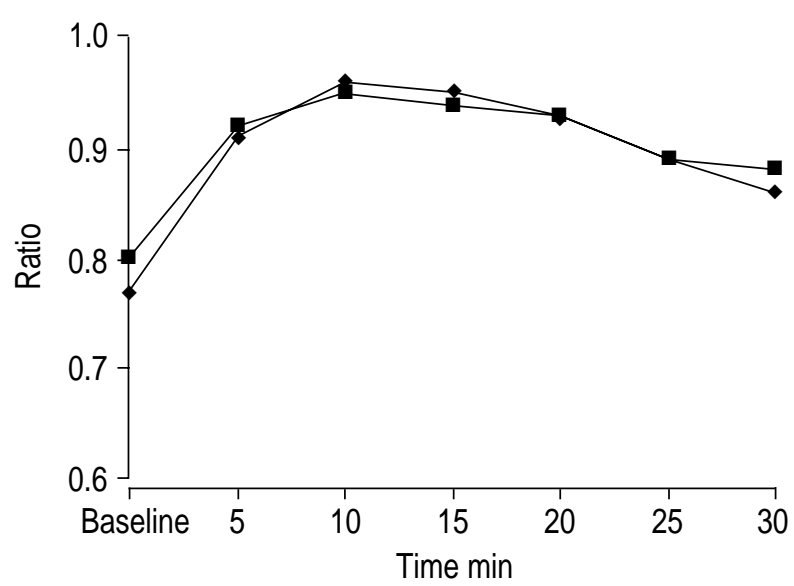

Fig. 3. - The changes of low frequency/high frequency power ratio components of heart rate variability after the salbutamol $(\diamond)$ and terbutaline $(\boldsymbol{\square})$ inhalation. 
agonist-induced changes of HRV may be due to increased $\beta$-receptor stimulation.

This study has some limitations. Respiration frequencies could not be determined simultaneously with the Holter monitoring. However, all subjects breathed quietly at rest during the Holter recordings. Thus, the effect of respiration on HRV was minimized. In addition, because study population consisted of patients who did not receive $\beta_{2}$-agonists for the previous 2 months, the results may be affected from receptor regulation in regular $\beta_{2}$-agonist use. Therefore, the results cannot be extrapolated to all asthmatic patients. The uncontrolled and unblind nature of this study was another limitation.

In conclusion, the present findings suggest that acute salbutamol and terbutaline inhalation elicited similar changes of heart rate variability and increased sympathetic modulation in the cardiac autonomic activity. Increased sympathetic activity may be implicated in the pathogenesis of a number of cardiovascular risk factors, including insulin resistance, hypertension, and the evolution of cardiovascular hypertrophy [25]. In addition, many recent studies have shown that patients with coronary artery disease and decreased vagal or increased sympathetic cardiac modulation, assessed by heart rate variability, have increased susceptibility to sudden coronary death, increased mortality and morbidity [26-28]. For these reasons, further studies are needed to evaluate the effects of salbutamol and terbutaline on cardiovascular autonomic activity and long-term cardiac mortality and morbidity in asthmatic patients with heart disease.

\section{References}

1. Task Force of European Society of Cardiology and the North American Society of Pacing and Electrophysiology. Heart rate variability, standards of measurement, physiological interpretation and clinical use. Circulation 1996; 93: 1043-1065.

2. Aubert AE, Ramaekers D. Neurocardiology: the benefits of irregularity. The basics of methodology, physiology and current clinical applications. Acta Cardiol 1999; 54: 107-120.

3. Singh N, Mironov D, Armstrong PW, Ross AM, Langer A. Heart rate variability assessment early after acute myocardial infarction: Pathophysiological and prognostic correlates. Circulation 1996; 93: $1388-$ 1395.

4. Bigger JT, Fleiss JL, Rolnitzky LM, Steinman RC. Frequency domain measures of heart period variability to assess risk late after myocardial infarction. J Am Coll Cardiol 1993; 21: 729-736.

5. Kleiger RE, Miller JP, Bigger JT, et al. Decreased heart rate variability and its association with increased mortality after acute myocardial infarction. $A m$ J Cardiol 1987; 59: 256-262.

6. Cripps TR, Malik M, Farrell TS, Camm AJ. Prognostic value of reduced heart rate variability after myocardial infarction: clinical evaluation of a new analysis method. Br Heart J 1991; 65: 14-19.

7. Singer DH, Martin GL, Magid N, et al. Low heart rate variability and sudden cardiac death. $J$ Electrocardiol 1988; 21: S46-S55.
8. Nolan J, Batin PD, Andrews R, et al. Prospective study of heart rate variability and mortality in chronic heart failure. Circulation 1998; 98: 1510-1516.

9. Ponikowski P, Anker SD, Tuan PC, et al. Depressed heart rate variability as an independent predictor of death in chronic congestive heart failure secondary to ischemic or idiopathic dilated cardiomyopathy. Am J Cardiol 1997; 79: 1645-1650.

10. Stein KM, Borer JS, Hochreiter C, et al. Prognostic value and physiological correlates of heart rate variability in chronic severe mitral regurgitation. Circulation 1993; 88: $127-135$.

11. Kazuma N, Otsuka K, Matsuoka I, Murata M. Heart rate variability during 24 hours in asthmatic children. Chronoblol Int 1997; 14: 597-606.

12. Garrard CS, Seidler A, McKibben A, McAlpine LE, Gordon D. Spectral analysis of heart rate variability in bronchial asthma. Clin Auton Res 1992; 2: $105-$ 111.

13. Skorodin MS. Beta adrenergic agonists: A problem. Chest 1993; 103: 1587-1590.

14. Barnes PJ. Current therapies for asthma: Promise and limitations. Chest 1997; 111: 17S-26S.

15. Jartti TT, Kaila TJ, Tahvanainen KUO, Kuusela TA, Vanto TT, Valimaki IAT. Altered cardiovascular autonomic regulation after 2-week inhaled salbutamol treatment in asthmatic children. Eur J Pediatr 1997; 156: $883-888$.

16. American Thoracic Society. Standards for the diagnosis and care of patients with chronic obstructive pulmonary disease and asthma. Am Rev Respir Dis 1987; 136: $225-244$.

17. Zahorska MB, Tkacz E, Kossmann S, Konieczny B, Hefczyc J, Nitka M. Circadian heart rate variability in asthma. Med Sci Monit 1997; 3: 52-56.

18. Jartti TT, Tahvanainen KU, Kaila TJ, et al. Cardiovascular autonomic regulation in asthmatic children evidenced by spectral analysis of heart rate and blood pressure variability. Scand J Clin Lab Invest 1996; 56: $545-554$.

19. Jartti T, Kaila T, Tahvanainen K, Valimaki IAT. The acute effects of inhaled salbutamol on the beat-to-beat variability of heart rate and blood pressure assessed by spectral analysis. Br J Clin Pharmacol 1997; 43: 421 428.

20. Rossinen J, Partanen J, Stenius AB, Aarniala B, Nieminen MS. Salbutamol inhalation has no effect on myocardial ischaemia, arrhythmias and heart-rate variability in patients with coronary artery disease plus asthma or chronic obstructive pulmonary disease. J Intern Med 1998; 243: 361-366.

21. Jartti TT, Kaila TJ, Tahvanainen KU, Kuusela TA, Vanto TT, Valimaki IAT. Altered cardiovascular autonomic regulation after salmeterol treatment in asthmatic children. Clin Physiol 1998; 18: $345-353$.

22. Penna AC, Dawson KP, Manglick P, Tam J. Systemic absorption of salbutamol following nebulizer delivery in acute asthma. Acta Pediatr 1993; 82: 963-966.

23. Scheinin M, Koulu M, Laurikainen E, Allonen H. Hypokalemia and other non-bronchial effects of inhaled fenoterol and salbutamol: A placebo-controlled dose-response study in healthy volunteers. $\mathrm{Br} \mathrm{J}$ Clin Pharmacol 1987; 24: 645-653.

24. Langer SZ. Presynaptic regulation of the release of catecholamines. Pharmacol Rev 1980; 32: 337-362. 
25. Palatini P, Julius S. Heart rate and cardiovascular risk. J Hypertens 1997; 15: 3-17.

26. Barron HV, Lesh MD. Autonomic nervous system and sudden cardiac death. J Am Coll Cardiol 1996; 27: $1053-1060$.

27. Schwartz PJ, La RM, Vanoli E. Autonomic nervous system and sudden cardiac death: experimental basis and clinical observations for post-myocardial infarction risk stratification. Circulation 1992; 85: Suppl. 1, 177-191.

28. Rich MW, Saini JS, Kleiger RE, Carney RM, TeVelde A, Freedland KE. Correlation of heart rate variability with clinical and angiographic variables and late mortality after coronary angiography. Am J Cardiol 1988; 62: 714-747. 